\title{
Enhancing Antitumor Efficacy of Cisplatin Low Dose by EDTA in Ehrlich Ascetic Carcinoma Bearing Mice
}

\author{
Sabry Ali El-Naggar ${ }^{1^{*}}$ \\ https://orcid.org/0000-0002-3001-795X \\ Karim Samy El-Said ${ }^{2}$ \\ https://orcid.org/0000-0003-1511-6033 \\ Maysa Mobasher ${ }^{3,4}$ \\ https://orcid.org/0000-0003-2987-0387 \\ Mohamed Elbakry ${ }^{2}$
https://orcid.org/0000-0002-3301-069X
}

${ }^{1}$ Tanta University, Faculty of Science, Zoology Department, Tanta, Egypt; ${ }^{2}$ Tanta University, Faculty of Science, Biochemistry Division, Chemistry Department, Tanta, Egypt; ${ }^{3}$ Jouf University, Faculty of Medicine, Pathology Department, Sakaka, Saudi Arabia; ${ }^{4}$ Ministry of Health, El Ahrar Educational Hospital, Clinical Pathology Department, Zagazig, Egypt.

Received: 2018.12.07; Accepted: 2019.08.16

"Correspondence: Karim Samy El-Said; e-mail: kareem.ali@science.tanta.edu.eg; kareem_samy2@yahoo.com; Tel.: (+2) 01002977062; Sabry Ali El-Naggar; E-mail: sabry.elnaggar@science.tanta.edu.eg; sabry_elnaggar@yahoo.com; Tel.: (+2) 01068382357

\section{HIGHLIGHTS}

- EDTA enhanced the antitumor efficacy of the low dose of Cisplatin.

- Low dose of Cisplatin did not inhibit tumor growth

- Co-treatment with EDTA delayed and decreased tumor growth.

- EDTA decreased the toxicity of Cisplatin.

Abstract: In a recent study, the treatment of different human cancer cell lines in vitro with ethylene diamine tetra-acetic acid (EDTA) showed a promising anticancer activity which could be a novel promising approach for cancer treatment. The aim of this study is to address the ability of EDTA to enhance the antitumor efficacy of the low dose of cisplatin (Cis) treatment in Ehrlich ascetic carcinoma (EAC) bearing mice. Sixty female albino mice were divided into six groups. The $1^{\text {st }}$ group of mice was served as a negative control. $2^{\text {nd }}-6^{\text {th }}$ groups were inoculated intraperitoneal (i.p) with $2 \times 10^{6}$ EAC cells/mouse. After one day of inoculation, the $2^{\text {nd }}, 3^{\text {rd }}$ and $4^{\text {th }}$ groups were injected daily for 6 days (early treatment) with phosphate buffer saline, low dose of Cis and Cis/EDTA, respectively. After six days, the $5^{\text {th }}$ and $6^{\text {th }}$ groups were injected with the low dose of Cis and Cis/EDTA for 6 consecutive days (late treatment), respectively. At day 14 , all groups of mice were sacrificed, sera were collected for biochemical assessment, 
then tumor volumes, counts, live and dead cells were determined from all groups. The results showed that EDTA co-treatment enhanced the efficacy of low dose of Cis at early and late time points. In addition, EDTA co-treatment potentially ameliorated the Cis-induced side effects on liver and kidney functions. In summary, co-therapy with EDTA could enhance the chemotherapeutic efficacy of low dose of Cis.

Keywords: Cisplatin; Antitumor; Ethylene diamine tetra-acetic acid (EDTA); Ehrlich ascites carcinoma.

\section{INTRODUCTION}

It is well known that ethylene diamine tetra-acetic acid (EDTA) promotes the depletion of some metals and alters some cellular physiological functions on the living organisms [1,2]. It modifies the enterocytes permeability of cell membranes, which in turn enhances the rate of absorption of some biomolecules and drugs [3]. Recently, EDTA has been tested in vitro as an anticancer agent against several human cancer cell lines. It has found to be a potent anticancer agent in vitro and might enhance the efficacy of conventional chemotherapies [4]. Furthermore, it has found that intratumoral EDTA injection enhanced the antitumor efficacy of cisplatin (Cis) on colonic cancer in rats [5]. We have recently reported that the treatment with EDTA alone did not show any antitumor activities against Ehrlich ascetic carcinoma (EAC) bearing mice. However, EDTA co-treatment with the therapeutic dose of $\mathrm{Cis}$ did not alter its antitumor efficacy [6]. Consistent with our findings, treatment with liposomes loaded with EDTA alone did not show any antitumor effects, however, liposomes loaded with EDTA and doxorubicin could significantly reduce drug toxicity without altering the antitumor activity [7]. EDTA administration enhances the antioxidant enzymes activity and decreases the hepatic inflammation and lipid peroxidation in carbon tetrachloride $\left(\mathrm{CCl}_{4}\right)$-induced liver fibrosis [8].

Cisplatin (Cis) is one of the most clinical chemotherapeutic drugs used for treatment of different types of cancer including bladder and cervical cancers $[9,10]$. Cis exhibited its antitumor effect via generating DNA adducts, which in turn leads to cell cycle arrest and initiating apoptotic signaling pathway [11]. However, nephrotoxicity is one of the most side effects of Cis treatment [12], oxidative stress induced by Cis has been recognized as a major factor of cardiotoxicity [13]. Treatment with a combination of quercetin and Cis ameliorates the nephrotoxicity side effect as well as enhanced antitumor activity [14]. Moreover, it has been reported that ibuprofen administration with Cis accelerates the apoptosis of cancer cells [15]. Cis concentrations used in treatment are significantly toxic to normal cells [16]. Finding new approaches to reduce Cis toxicity and increase its antitumor efficacy at low dose is an ultimate need. In this study, our aim is to address the direct effect of EDTA treatment on the antitumor efficacy of Cis low dose.

\section{MATERIAL AND METHODS}

Cisplatin (Cis-diamminedichloroplatinum II) was purchased from Sigma-Aldrich (St Quentin Fallavier, France). Vials were diluted by phosphate buffer saline (PBS) and the concentration was adjusted to $0.5 \mathrm{mg} / \mathrm{Kg} \mathrm{B} . \mathrm{Wt}$ in $200 \mu \mathrm{l}$ [17]. Ethylene diamine tetraacetic acid (EDTA) was purchased from Sigma (Sigma-Aldrich, CO. LLC., USA) and reconstituted by PBS to final concentration of $25 \mathrm{mg} / \mathrm{Kg}$ in $200 \mu \mathrm{l}$.

\section{Mice}

Female Swiss albino mice weighting $20 \pm 2 \mathrm{~g}$ were obtained from National Research Center (NRC, Cairo, Egypt). Animals were housed (5/cage), in 12 h/12 h dark/light cycle under laboratory condition of temperature and humidity. Mice were 
kept for a week before starting the experiment for adaptation and then handled according to the ethical guidelines approved by the animal care and use committee, Faculty of Science, Tanta University (ACUC-SCI-TU), Egypt.

\section{Ehrlich Ascites Carcinoma (EAC) Tumor Cells Inoculation}

The EAC cells were collected from the tumor bearing mice purchased from the National Cancer Institute ( $\mathrm{NCl}$, Cairo, Egypt). The viable and dead cells were counted using trypan blue method; total viable cells were calculated as following: Mean number of unstained cells $\times$ dilution $\times 10^{4}$. The number of tumor cells was adjusted at $2 \times 10^{6}$ cells/mouse for intraperitoneal (i.p) inoculation.

\section{Experimental Design}

Sixty (60) female albino mice were divided into six groups $(n=10)$. The $1^{\text {st }}$ group (Gp1) was used as a negative control. From the $2^{\text {nd }}$ to the $6^{\text {th }}$ groups of mice were inoculated i.p with $2 \times 10^{6}$ EAC cells mouse. After $24 \mathrm{~h}$ post EAC tumor cells inoculation, $2^{\text {nd }}, 3^{\text {rd }}$, and $4^{\text {th }}$ groups of mice were injected daily for 6 days (early treatments) with 200 $\mu \mathrm{l}$ of PBS, low dose of Cis $(0.5 \mathrm{mg} / \mathrm{Kg})$ and Cis/EDTA $(25 \mathrm{mg} / \mathrm{Kg})$, respectively. The $5^{\text {th }}$ and $6^{\text {th }}$ groups of mice were injected with a low dose of Cis and Cis/EDTA, for 6 consecutive days starting from day 6 to day 12 (late treatments), respectively. At day 14 , all mice in the above-mentioned groups were bled via the orbital plexus to collect blood samples, and then centrifuged to collect sera for biochemical analysis. Then, mice were sacrificed to harvest tumor cells, then tumor volumes, counts, live and dead cells were assessed.

\section{Determination of Total Body Weight Changes}

All groups of mice were weighted at the beginning (day 0 ) and at the end of the experiment (day 14). The percentage of the change in the total body weight (T.B.W) was calculated as follow: (T.B.W at day (14) - T.B.W at day (0) / T.B.W at day (0)) $\times$ 100.

\section{Flow Cytometer Analysis}

To determine EAC cell apoptosis after treatment, briefly, EAC cells were collected from the abdominal cavity of the different groups of mice, then washed twice with cold PBS and then re-suspended in $1 \mathrm{X}$ binding buffer at a concentration of $3 \times 10^{6} \mathrm{cells} / \mathrm{ml}$. Five $\mu \mathrm{l}$ of Annexin-V and $5 \mu \mathrm{l}$ Propidium lodide (PI) were added to $100 \mu \mathrm{l}$ of cell suspension. Then, the cells were gently shacked and incubated for 15 min at room temperature $\left(25^{\circ} \mathrm{C}\right)$ in the dark. Place $400 \mu \mathrm{l}$ of $1 \mathrm{X}$ binding buffer were added and then analyzed by BD FACSC anto ${ }^{\mathrm{TM}}$ II flow cytometer.

\section{Biochemical Analysis}

Serum alanine transaminases (ALT), aspartate transaminases (AST), urea and creatinine were determined by the colorimetric methods using kits (DiamondDiagnostics, Egypt).

\section{Statistical Analysis}

One-way analysis of variance (ANOVA) was used to assess the significant differences among treatment groups. Dunnet test was used to compare all groups against the control group to show the significant effect of treatment. The criterion for statistical significance was set at $p<0.05$ or $p<0.01$. All data are presented as mean \pm SD. 


\section{RESULTS}

\section{Co-Treatment of EDTA with Low Dose of Cis Decreased the Total Body Weight Changes}

We have reported previously that the co-treatment with EDTA along with Cis (2 $\mathrm{mg} / \mathrm{Kg}$ ) at early time point did not alter the antitumor efficacy of Cis. We have also reported that EDTA treatment alone did not show any antitumor activity against EACbearing mice [6]. In this study, the percentages (\%) of the change in the total body weight (T.B.W) were monitored by weighting animal groups at the beginning (D 0$)$ and at the end of the experiment (D 14). The results showed that group of mice which inoculated with tumor cells (Gp2) led to a significant increase in the T.B.W (50\%). The group of mice which daily treated with low dose of Cis $(0.5 \mathrm{mg} / \mathrm{Kg} / 6$ days $)$ starting from day 1 to day 6 (early treatment) showed a significant decrease in the T.B.W (20\%). Co-treatment of EDTA $(25 \mathrm{mg} / \mathrm{Kg})$ at early time point along with Cis treatment (Gp4) led to a highly significant decrease in T.B.W (5\%). Group of mice (Gp5) treated daily with low dose of Cis starting from day 6 to day 12 (late treatment) showed a decrease in T.B.W when compared with the group of mice inoculated with tumor cells alone (Gp2). Similarly, the group of mice co-treated with EDTA and low dose of Cis (Gp6) showed a significant decrease in the T.B.W (Figure 1).

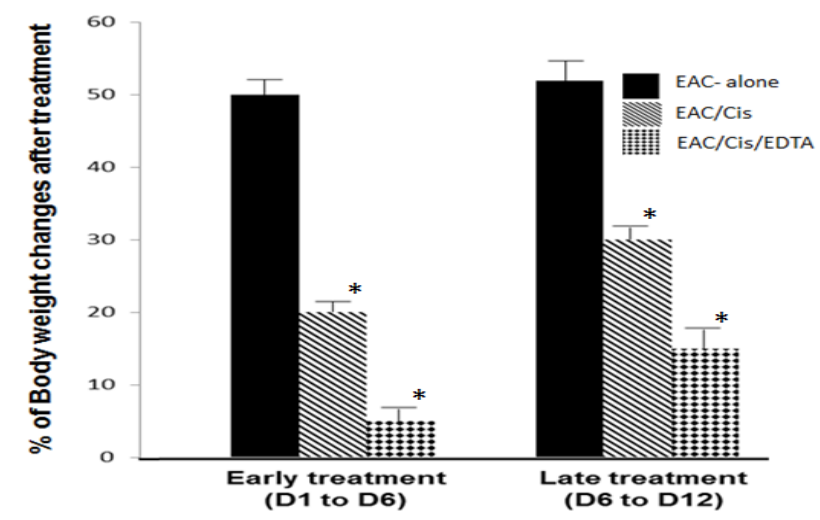

Figure 1. The total body weight change (T.B.W) in all groups under study. Mice inoculated with EAC-cells alone (Gp2), treated either with low dose of Cis alone (Gp3) or with low dose of Cis/EDTA (Gp4) at early time points (day 1 to day 6), Gp5 and Gp6 treated as Gp3 and Gp4 but at late time points (day 6 to day 12). The body weight changes (T.B.W) was calculated as follow: (T.B.W at day (14) - T.B.W at day (0) / T.B.W at day (0)) $\times 100$.

\section{Co-Treatment with EDTA Along with Low Dose of Cis Significantly Decrease the Tumor Volumes and Their Viability}

We further aimed to investigate the direct effect of EDTA on the antitumor efficacy of low dose of Cis $(0.5 \mathrm{mg} / \mathrm{Kg})$ at early and late time points. The results showed that EDTA co-treatment led to a significant decrease in the total tumor volume, tumor cells count, and their viability as compared to tumor bearing mice alone and tumor bearing mice treated with the low dose of Cis alone (Table 1 and Figure 2). As shown in Fig. 2 A, B and C, the group of mice which treated with low dose Cis/EDTA (Gp4) showed a small ascetic volume as compared to their control in Gp2 and Gp3. In addition, it was noticed that, the tumor cells aggregated as masses of dead cells due to the treatment with low dose Cis/EDTA (Fig. 2D). Similar to the results obtained at the early treatment setting with Cis alone or with Cis/EDTA, the late treatment with low dose of Cis/EDTA (Gp6) led to a decrease in the abdomen ascites volume when compared to their control (Gp2) or with mice which administrated with low dose of Cis alone (Gp5) (Figure 3). 
Table 1. EAC volumes, counts and cells viability of the different groups under study at early and late points of treatments.

\begin{tabular}{lcccc}
\hline Groups & $\begin{array}{c}\text { Total } \\
\text { volume } \\
(\mathbf{m L})\end{array}$ & $\begin{array}{c}\text { Total count } \\
\left(\times 10^{6} / \text { mouse }\right)\end{array}$ & $\begin{array}{c}\text { Viable cells } \\
\left(\times 10^{6} / \text { mouse }\right)\end{array}$ & $\begin{array}{c}\text { Dead cells } \\
\left(\times 10^{6} / \text { mouse }\right)\end{array}$ \\
\hline Gp2 & $11 \pm 1.21^{\mathrm{a}}$ & $991 \pm 7.5^{\mathrm{a}}$ & $989.4 \pm$ & $1.6 \pm 0.91^{\mathrm{e}}$ \\
& & & $1.26^{\mathrm{a}}$ & \\
Gp3 $^{\star}$ & $4 \pm 0.13^{\mathrm{b}, \mathrm{c}}$ & $32 \pm 1.5^{\mathrm{d}}$ & $22 \pm 0.350^{\mathrm{d}}$ & $10 \pm 0.25^{\mathrm{c}}$ \\
Gp4 $^{\star}$ & $2 \pm 1.52^{\mathrm{c}}$ & $20 \pm 0.970^{\mathrm{d}}$ & $14 \pm 0.430^{\mathrm{e}}$ & $6 \pm 0.69^{\mathrm{d}}$ \\
Gp5 $^{\star *}$ & $6 \pm 0.13^{\mathrm{b}}$ & $300 \pm 1.5^{\mathrm{b}}$ & $210 \pm$ & $90 \pm 0.33^{\mathrm{a}}$ \\
& & & $0.170^{\mathrm{b}}$ & \\
Gp6 $^{\star *}$ & $4 \pm 1.02^{\mathrm{b}, \mathrm{c}}$ & $120 \pm 1.09^{\mathrm{c}}$ & $70 \pm 0.16^{\mathrm{c}}$ & $50 \pm 0.910^{\mathrm{b}}$ \\
\hline F- Value & 36.46 & 15303.07 & 1123331.66 & 9394.14 \\
\hline P-Value & 0.000 & 0.000 & 0.000 & 0.000 \\
\hline
\end{tabular}

Gp2: EAC-bearing mice, Gp3 and Gp5: EAC/Cis (0.5 mg/Kg), Gp4 and Gp6: EAC/Cis $(0.5$ $\mathrm{mg} / \mathrm{Kg}$ )/EDTA $\left(25 \mathrm{mg} / \mathrm{Kg}\right.$ ), ${ }^{*}$ groups of mice which treated from $D 1$ to $D 6 .{ }^{* *}$ groups of mice which treated from D6 to D12. ${ }^{* *}$ Tukey Pairwise Comparisons means that do not share a letter are significantly different.
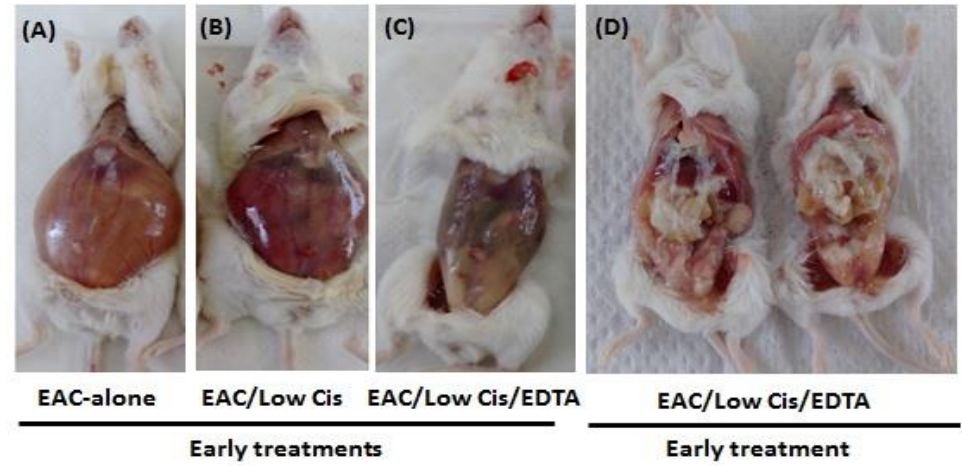

Figure 2. Photomicrographs showed the tumor sizes after early treatment with low dose of Cis alone or with low dose of Cis/EDTA. A) EAC-bearing mice with no treatment and served as a control (Gp2), B) tumor-bearing mice injected with low dose of Cis (Gp3), C and D) tumorbearing mice injected with low dose of Cis/EDTA (Gp4). The treatment protocol (early) was applied starting from day 1 to day 6 post EAC-cells inoculations.

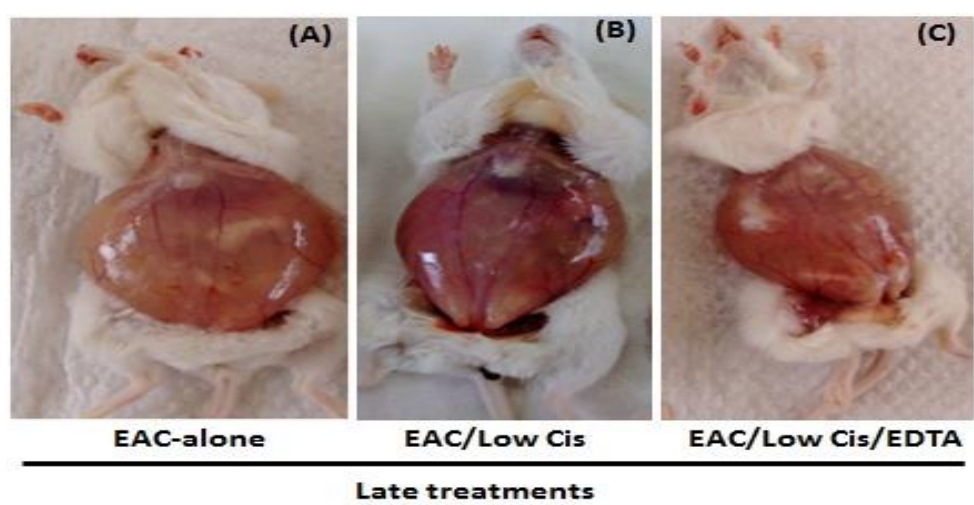

Figure 3. Photomicrographs showed the tumor sizes after late treatment with the low dose of Cis alone or with EDTA. A) EAC-bearing mice with no treatment and served as a control, B) tumor-bearing mice injected with low dose of $\mathrm{Cis}, \mathrm{C}$ ) tumor-bearing mice injected with low dose of Cis/EDTA. The treatment protocol (late) was applied starting from day 6 to day 12 post EACcells inoculations. 


\section{Flow Cytometer Analysis}

The percentage of the EAC- apoptotic cells was determined by flow cytometer after early and late treatments with low dose of Cis alone or with low dose Cis/EDTA. The results showed that the treatment with low dose of $C$ is alone at early time point induced EAC cells apoptosis more than their control. The early treatment with low dose of Cis/EDTA increased the percentage of EAC-cells apoptosis to $14 \%$ (Figure $4 \mathrm{a}$ ). Interestingly, at late treatment with Cis/EDTA, the percentage of tumor apoptotic cells increased to $15 \%$ as compared to their control (2.5\%) (Figure 4 b).

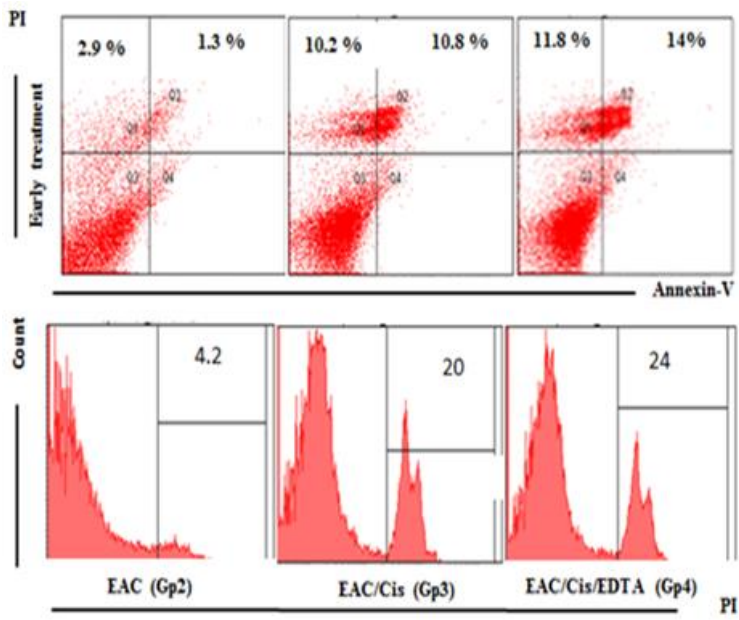

(a)

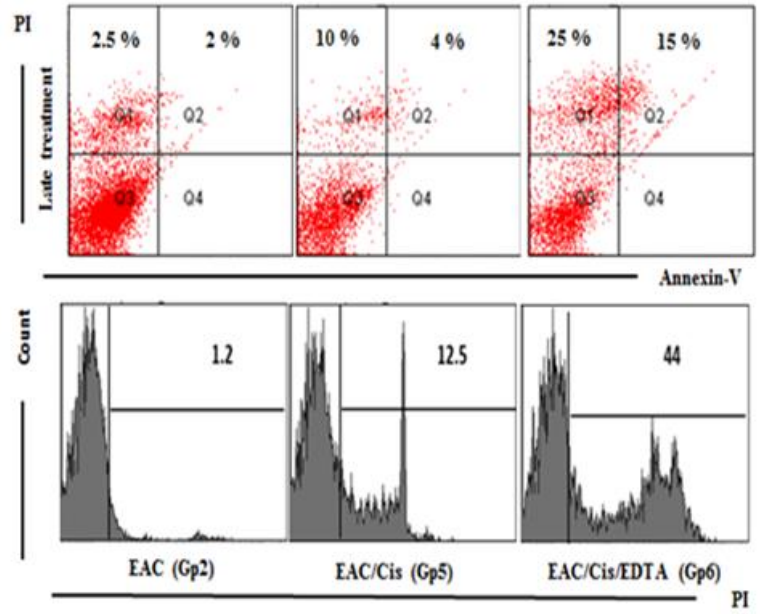

(b)

Figure 4. The percentages of apoptotic tumor cells. (A) Early treatment with low dose of Cis $(0.5 \mathrm{mg} / \mathrm{kg})$ or with Cis/EDTA (25 mg/kg) starting from day 1 to day 6 post tumor cells inoculations. (B) Late treatment from day 6 to day 12 post tumor cells inoculations. Mice were inoculated with $2 \times 10^{6} \mathrm{EAC}$-cells/mouse, Gp2 served as control (EAC-inoculated mice), Gp3 and 5 were treated with low dose of Cis at early and late time points, respectively. Gp4 and 6 were treated with low dose of Cis/EDTA at early and late time points, respectively. After 14 days from cell inoculation, tumor cells were harvested and washed twice with PBS, then stained with Annexin- $\mathrm{V}$ and $\mathrm{PI}$ to determine the apoptotic percentages.

\section{Co-Treatment with Low Dose of Cis Along with EDTA Improved of Liver and Kidney Functions}

Treatment with low dose of Cis/EDTA for the same time either at early or late time points led to slightly enhancement in the levels of alanine transaminases (ALT), aspartate transaminases (AST), urea and creatinine as compared to their levels in the group of mice which inoculated with EAC cells alone (Gp2) or with groups administrated with low dose of Cis alone at early and late treatments (Gp3 and 5) (Table 2). 
Table 2. Serum alanine aminotransferase (ALT), aspartate aminotransferase (AST), urea, and creatinine in the different groups.

\begin{tabular}{|c|c|c|c|c|}
\hline \multirow[b]{2}{*}{ Groups } & \multicolumn{4}{|c|}{ Biochemical parameters } \\
\hline & $\begin{array}{l}\text { ALT } \\
(\mathrm{U} / \mathrm{L})\end{array}$ & $\begin{array}{l}\text { AST } \\
\text { (U/L) }\end{array}$ & $\begin{array}{c}\text { Urea } \\
\text { (mg/dL) }\end{array}$ & $\begin{array}{l}\text { Creatinine } \\
(\mathrm{mg} / \mathrm{dL})\end{array}$ \\
\hline Gp1 & $24.71 \pm 1.47^{e}$ & $50.66 \pm 2.52^{f}$ & $29.01 \pm 1.0^{f}$ & $0.31 \pm 0.09^{e}$ \\
\hline Gp2 & $68.10 \pm 1.53 b$ & $160.83 \pm 2.41^{\mathrm{c}}$ & $64.66 \pm 0.76^{c}$ & $0.73 \pm 0.06^{c}$ \\
\hline Gp3* & $79.73 \pm 1.20^{a}$ & $191.16 \pm 3.06^{a}$ & $86.93 \pm 0.50^{a}$ & $1.71 \pm 0.08^{\mathrm{a}}$ \\
\hline Gp4* & $50.98 \pm 1.0^{d}$ & $98.33 \pm 2.07^{e}$ & $47.63 \pm 0.85^{\mathrm{e}}$ & $0.60 \pm 0.07^{d}$ \\
\hline Gp5 $5^{\star *}$ & $71.23 \pm 1.14^{b}$ & $178.23 \pm 3.04^{b}$ & $82.73 \pm 0.67^{b}$ & $1.41 \pm 0.02^{b}$ \\
\hline Gp6 $6^{\star *}$ & $61.08 \pm 2.65^{c}$ & $127.13 \pm 2.14^{d}$ & $52.43 \pm 0.92^{d}$ & $0.83 \pm 0.07^{c}$ \\
\hline F- Value & 485.68 & 1468.42 & 2343.09 & 183.22 \\
\hline P-Value & 0.000 & 0.000 & 0.000 & 0.000 \\
\hline
\end{tabular}

\section{DISCUSSION}

Ethylene diamine tetra-acetic acid (EDTA) has some medical and therapeutic uses such as metal chelator in treatment of lead and iron toxicity [6]. The chelation properties of EDTA are also employed to prevent blood coagulation [7], preserve ophthalmic preparations [8] and to decrease the complications of certain types of anemia and blood transfusion [9]. The Cr (III) complex with EDTA is used in medical diagnosis to assess the glomerular filtration rate [10]. EDTA was also used as an antimicrobial agent for wound care [10] and intraocular lens implantation [12]. The lowest reported toxic dose of EDTA was found to be $750 \mathrm{mg} / \mathrm{kg} / \mathrm{day}$ [13].

This study was conducted to address the impact of the co-treatment with EDTA along with the treatment with the low dose of Cis. Our previous data showed that EDTA treatment has no antitumor effects against EAC-bearing mice. Furthermore, the treatment with EDTA along with the therapeutic dose of Cis $(2 \mathrm{mg} / \mathrm{Kg} / 6$ days) did not alter Cis efficacy as anticancer agent. In this study, we have reported that the treatment with EDTA along with the low dose of Cis enhanced the anticancer efficacy Cis either at early or late time points of the treatments. The data showed that the change in the total body weigh was increased up to $50 \%$ after 14 days of EAC-cells inoculation and this increase due to the development of a large volume of ascetic tumor cells in the peritoneal cavity and this finding was in agreement with the earlier observations on EAC mice model [18]. After the treatment with the low dose of $\mathrm{Cis}(0.5 \mathrm{mg} / \mathrm{Kg})$ at early time points (from day 1 to day 6 post-EAC-cells inoculation), the change in the total body weight were decreased due to the antitumor effect of Cis. This finding was in agreement with several publications, which used this model for drug screening $[19,20]$.

Interestingly, the co-treatment with EDTA and low dose of Cis significantly decreased the change in the total body weight when compared with their EAC-tumor bearing mice or with EAC-tumor bearing mice treated with the low dose of Cis at early or late time points. These findings indicated that the EDTA treatments have a potential effect on the enhancing the chemotherapeutic effect of the low dose of Cis either at early or late time points of the treatments. This finding was confirmed with the changes in the total volume of the tumor among different groups under the treatments when compared to their control group. The results showed that the group of mice, which treated with EDTA/Cis at early or late time points, had low tumor volumes as compared to other treated groups. Furthermore, the percentage of the apoptotic cells in the groups of mice with treated with EDTA/Cis showed the highest apoptotic value when compared to their control group or with the groups of mice which treated with low dose of $\mathrm{Cis}$ alone at early or late time points. This data confirmed the role of EDTA cotreatment on enhancing the effect of the low dose of Cis as anticancer agents. 
Preclinical report demonstrated that EDTA could improve the platinum accumulation in tumors, increasing drug diffusion through the tumor matrix and enhancing the antitumor efficacy [5]. Furthermore, recent study determined the potential anticancer activity of EDTA on six different human cancer cell lines (U937, C-32, HeLa, HSC-2, Molt-4, and U87-MG) [4]. Another study showed that EDTA treatment led to change in the subcellular expressions of the clusterin protein in colon adenocarcinoma COLO 205 cells, which accompanied by extensive death of cancer cells [21].

The enhancement of the antitumor efficacy of the low dose of Cis up on cotreatment with EDTA could be due to the increase the cellular permeability of EAC cells, which in turn could increase the effect of Cis. Consequently, our data showed that the treatment with EDTA and the low dose of Cis significantly improve both of liver and kidney functions when compared to the groups of mice, which treated with the low dose of Cis alone or with the group of mice which inoculated with EAC-cells alone. This finding was in agreement with our previous studies, which showed that the treatment with Cis induces organs toxicity and increased the levels of liver enzymes, urea and creatinine [19,22]. Therefore, co-treatment with EDTA and the low dose of Cis consider a new approach to enhance Cis efficacy and decrease its side effects.

\section{CONCLUSION}

The co-treatment with EDTA along with low dose of cisplatin lead to enhancement of the antitumor efficacy of low dose cisplatin and slightly decrease its toxic effects on the liver and kidneys organs.

\section{REFERENCES}

1. Barfell A, Crumbly A, Romani A. Enhanced glucose 6-phosphatase activity in liver of rats exposed to $M g^{(2+)}{ }^{(-d e f i c i e n t ~ d i e t . ~ A r c h i v e s ~ o f ~ B i o c h e m i s t r y ~ a n d ~ B i o p h y s i c s . ~ 2011 ; ~ 509: 157-~}$ 63.

2. El-Naggar S, El-Said K, Othman S, Mansour F, Kabile D, Khairy M. Cooking with EDTA reduces nutritional value of Vicia faba beans. Biotechnology Reports. 2019;22:e00322.

3. Tomita, M.; Hayashi, M.; Awazu, S. Absorption enhancing mechanism of EDTA, caprate, and decanoylcarnitine in Caco-2 Cells. Journal of Pharmaceutical Science. 1996;85;608-11.

4. Feril JR, Ogawa K, Watanabe A, Ogawa R, Zheng-Guo C, Takashi K, Katsuro T. Anticancer Potential of EDTA: A Preliminary in Vitro Study. Mathews Journal of Cancer Science. 2017; 1:1-009.

5. Duvillard C, Ponelle T, Chapusot C, Piard F, Romanet P. EDTA enhances the antitumor efficacy of intratumoral cisplatin in s.c. grafted rat colon tumors. Anticancer drugs. 2004; 15:295-9.

6. El-Naggar SA, EI-Said KS. Antitumor efficacy of EDTA co-treatment with cisplatin in tumorbearing mice. Brazilian Journal of Pharmaceutical Sciences (In Press).

7. Song Y, Huang Z, Song Y, Tian Q, Liu X, She Z, et al. The application of EDTA in drug delivery systems: doxorubicin liposomes loaded via $\mathrm{NH}_{4}$ EDTA gradient. International Journal of Nanomedicine. 2014; 9:3611-21.

8. González-Cuevas J, Navarro-Partida J, Marquez-Aguirre AL, Bueno-Topete MR, BeasZarate C, Armendáriz-Borunda J. Ethylenediaminetetraacetic acid induces antioxidant and anti-inflammatory activities in experimental liver fibrosis. Redox Report. 2011; 16:62-70.

9. Coppin C, Gospodarowicz MK, James K, Tannock IF, Zee B, Carson J, et al. Improved local control of invasive bladder cancer by concurrent cisplatin and preoperative or definitive radiation. Journal of Clinical Oncology. 1996; 14:2901-7.

10. Rose PG, Bundy BN, Watkins EB, Thigpen JT, Deppe G, Maiman MA, et al. Concurrent cisplatin-based radiotherapy and chemotherapy for locally advanced cervical cancer. New England Journal of Medicine. 1999; 340:1144-53. 
11. Sorenson CM, Eastman A. Influence of cis-diamminedichloroplatinum(II) on DNA synthesis and cell cycle progression in excision repair proficient and deficient Chinese hamster ovary cells. Cancer Research. 1988; 48:6703-7.

12. Chvetzoff G, Bonnotte B, Chauffert B. Anticancer chemotherapy. Prevention of toxicity. Press medical. 1998; 27:2106-12.

13.El-Sawalhi MM, Ahmed LA. Exploring the protective role of apocynin a specific NADPH oxidase inhibitor in cisplatin-induced cardiotoxicity in rats. Chemico-biological Interaction. 2014; 207:58-66.

14.Li Q, Liang Y, Hu G, Tian Y. Enhanced therapeutic efficacy and amelioration of cisplatininduced nephrotoxicity by quercetin in 1,2-dimethyl hydrazine-induced colon cancer in rats. Indian Journal Pharmacology. 2016; 48:168-71.

15. Endo H, Yano M, Okumura Y, Kido H. Ibuprofen enhances the anticancer activity of cisplatin in lung cancer cells by inhibiting the heat shock protein 70. Cell Death and Diseases. 2014;5: e1027.

16. Bhat SG, Mishra S, Mei Y, Nie Z, Whitwort CA, Rybak LP, et al. Cisplatin up-regulates the adenosine $A 1$ receptor in the rat kidney. European Journal Pharmacology. 2002; 442:25164.

17.Treskes M, Boven E, Holwerda U, Pinedo HM, van der Vijgh WF. Time Dependence of the Selective Modulation of Cisplatin-induced Nephrotoxicity by WR2721 in the Mouse. Cancer Research. 1992; 52:2257-60.

18.Jagetia GC, Baliga MS. Effect of Alstonia scholaris in enhancing the anticancer activity of berberine in the Ehrlich ascites carcinoma-bearing mice. Journal of Medicinal Food. 2004; 7:235-44.

19.El-Naggar SA. Lack of the beneficial effects of mirazid (Commiphora molmol) when administered with chemotherapeutic agents on Ehrlich ascetic carcinoma bearing mice. Advances in Biological Research. 2011; 5:193-9.

20.Pai KR, Srilatha P, Suryakant K, Manjunath SM, Nayak G, Mallikarjuna Rao C, Baliga MS. Anticancer activity of Berberis aristata in Ehrlich ascites carcinoma-bearing mice. Pharmaceutical Biology. 2012; 50:270-7.

21.Pajak B, Orzechowski A. Ethylenediaminetetraacetic acid affects subcellular expression of clusterin protein in human colon adenocarcinoma COLO 205 cell line. Anticancer drugs. 2007; 18:55-63.

22. Ibrahim MA, Bakhaat GA, Tammam HG, Mohamed RM, El-Naggar SA. Cardioprotective effect of green tea extract and vitamin $\mathrm{E}$ on Cisplatininduced cardiotoxicity in mice: Toxicological, histological and immunohistochemical studies. Biomedicine \& Pharmacotherapy. 2019; 113:108731. BY NC) license (https://creativecommons.org/licenses/by-nc/4.0/). 